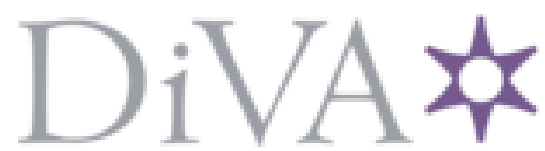

http://www.diva-portal.org

\title{
Postprint
}

This is the accepted version of a paper published in International Journal of Health Care Quality Assurance. This paper has been peer-reviewed but does not include the final publisher proofcorrections or journal pagination.

Citation for the original published paper (version of record):

Kjellström, S., Andersson, A-C. (2017)

Applying adult development theories to improvement science.

International Journal of Health Care Quality Assurance, 30(7): 617-627

https://doi.org/10.1108/IJHCQA-09-2016-0124

Access to the published version may require subscription.

N.B. When citing this work, cite the original published paper.

Permanent link to this version:

http://urn.kb.se/resolve?urn=urn:nbn:se:hj:diva-37178 


\section{Applying Adult Development Theories to Improvement Science}

Author 1: Sofia Kjellström, PhD, Associate Professor, Researcher and Senior Lecturer, Jönköping Academy for Improvement of Health and Welfare, Jönköping University, Jönköping, Sweden, Telephone: +4636 101313, e-mail: sofia.kjellstrom@ju.se

Author 2: Ann-Christine Andersson, RN, PhD, Researcher and Senior Lecturer, Jönköping Academy for Improvement of Health and Welfare, Jönköping University, Jönköping, Sweden, Telephone: +46 36 101315, e-mail: ann-christine.andersson@ju.se

Corresponding author: Sofia Kjellström

Corresponding Author's E-mail: sofia.kjellstrom@ju.se

\section{Structured Abstract:}

Purpose: This article addresses how adult development theories can contribute to quality improvement.

Design/Methodology/Approach: A theoretical analysis and discussion on how personal development empirical findings can relate to quality improvement (QI) and Deming's four improvement knowledge domains.

Findings: Adult development research shows that professionals have qualitatively diverse ways of meaning-making and ways to approach possibilities in improvement efforts. Therefore, professionals with more complex meaning-making capacities are needed to create successful transformational changes and learning, with the recognition that system knowledge is a developmental capacity.

Research and practical implications: In QI and improvement science (IS) there is an assumption that professionals have the skills and competence needed for improvement efforts, but adult development theories show that this is not always the case, which suggests a need for facilitating improvement initiatives, so that everyone can contribute based on their capacity.

Originality/value: This study illustrates that some competences in QI efforts are a developmental challenge to professionals, and should be considered in practice and research.

Keywords: Quality improvement; Change management; Leadership; Quality healthcare; Continuing professional development.

Article classification: Conceptual

Received $-10^{\text {th }}$ Sep 2016

Revised $-5^{\text {th }}$ Apr 2017

Accepted $-14^{\text {th }}$ May 2017 


\section{Introduction}

Knowledge about change and development have evolved along with modern systems and organizations, but still, despite our health and wellbeing knowledge, there are many issues to address, and gaps between what we know and what we do (IoM, 2001). Improvement science (IS) is an emerging research field, which tries to build knowledge on how to change for the better and create quality improvement (QI) in health and welfare organizations. We recognize that IS needs to be supplemented and supported by knowledge from other natural and social sciences (Bergman et al., 2015). We address what IS can learn and gain from adult development studies, a research area that analyses people`s sequential evolution through life. Adult development and IS research areas, therefore, address change and development.

\section{Improvement science}

Improvement science is an emerging discipline that explores how staff can change to improve performance. Even though IS is based upon knowledge created from existing quality improvement (QI) strategies, the term was first used in 1996 (Langley et al., 2009; Bergman et al., 2015) and it has been applied to areas as divergent as the automotive industry and healthcare (Langley et al., 2009). Dividing knowledge is essential in IS. First, there is professional or subject matter knowledge on what is state-of-the-art in a context or area (e.g., what leadership is needed for a specific task in a unique context). Second, improvement knowledge is about what information is needed in an organization to produce changes that ultimately result in improvement (Batalden and Davidoff, 2007; Langley et al., 2009). This improvement knowledge is called a profound knowledge system by Deming, a pioneer in the discipline. Deming (2000) distinguished four improvement knowledge domains and many writings have taken his areas as a starting point for describing what IS is about: (i) appreciating a system; (ii) knowledge about variation; (iii) knowledge theory; and (iv) psychology. These vary in scope, but the four domains need to be broadened with more recent knowledge from different domains. To understand IS, a distinction between IS and QI is needed. Both are about quality and development, but with different foci. Quality improvement is knowledge of models and methods developed to improve what is done in practice. Improvement science focuses on the research aspect, trying to study and evaluate what QI methods and models work, where and why (Langley et al., 2009); in Deming's words 'gaining knowledge’ (ibid, p. 82). Thus, IS, as a research field, investigates QI efforts. Key terms are used interchangeably and that interpretation has changed over time. Several expressions are and have been used (e.g., quality improvement, continuous improvement and quality assurance) and there is also a conceptual change in that what was previously called QI research, is now called IS (or improvements science).

\section{Quality improvement knowledge}

Quality improvement has its origin in production organizations, where managers aim to produce more effectively. In health and welfare, QI has become an important aspect for service safety and effectiveness reasons while delivering better quality care (Riley et al., 2010). Quality improvement, or at least the idea, has become a competition issue. One established QI definition (in health and welfare) is 'to make the changes that will lead to better patient outcomes, better system performance and better professional development' (Batalden and Davidoff, 2007, p.2). This definition ties together the focus (better patient outcomes) with the necessary means (professional and system development). Donabedian, another healthcare QI pioneer, describes quality in health and welfare settings as combining science and technology with their application in practice (Donabedian, 2003), which agrees with the intention that IS research should be practical 
(Ting et al., 2009). New research findings and technology should be developed together with those who use them; thus, IS aims to find meaning and practical applications (Marshall et al., 2013) but also connects to organizational learning (Senge, 2000; Argyris, 1999).

\section{System knowledge}

One contribution from Deming was about understanding the organization as a system. Health and welfare professionals are too often ignorant illiterate regarding system and process thinking (Hovlid et al., 2012), which causes problems, since knowledge about processes is needed for improving performance (Batalden and Davidoff, 2007). A system approach includes taking all stakeholders into account and knowing how people interact with system structures and processes. A system thinking model frequently used in QI, especially in health and welfare organizations, is micro-system thinking (Nelson et al., 2007). Understanding different perspectives (i.e., micro, meso, macro) and their interdependence is crucial (Mohr and Batalden, 2002), as change does not happen in a vacuum. System knowledge also builds upon the assumption that all system parts are interrelated with all other system parts and cannot be understood in isolation, which also means that there is no simple linear cause and effect determination. Systems can be simple, complicated or complex (Glouberman and Zimmerman, 2002). Complex systems are not linear, but often act as networks, containing many agents (or users) that interact with each other in different ways at different times. To manage complex systems, agents need to be adaptive, which means that they must learn how to adapt to changes both inside and outside themselves (Palmberg, 2009).

\section{Knowledge theory}

Knowledge domain explains what and how a person can know. Quality improvement projects are often handled as black boxes, where something goes in at one end and something comes out at the other end. To learn from that process, professionals need to know what is happening. Deming (2000) used the terms education and development, which can be formulated as time for reflection, a way to create meaning and adopt new knowledge. Reflection helps staff to learn, create understanding and draw meaning from their experiences (Hovlid et al., 2012; Palmberg, 2009). Deming is particularly known for championing the Plan-Do-Study-Act (PDSA) cycle, initially conceptualized by Walter Shewart (Langley et al., 2009) - a process that tests a change effort, where reflection is interwoven with action or planning a change (Plan); carrying out the change (Do); observing and learning from the consequences (Study); and reflecting on modifications to change effort (Act). Bergman et al., (2015) suggest an important QI factor is how individuals make up and transform their creating meaning ways. The authors call for more knowledge about how second-order change can be achieved by integrating current research on transformative learning (Mezirow, 1991) and learning to learn (Argyris, 1999). First-order learning is when persons learn something in their current understanding. But change at the system level often requires transformational or second-order learning, which means that persons need to change their way of understanding. There is also third-order learning, when persons reflect on themselves and their current way of making meaning. Senge (2000) argues that change depends on staff adaption capability, also emphasized in system thinking, meaning that staff in complex systems can learn and adapt through their own experiences (Glouberman and Zimmerman, 2002).

\section{Change - the human side}

Psychology is described as one of four inseparable central principles in Deming's profound knowledge system (Batalden and Stoltz, 1993). Deming understood that people are different and motivated by different things. In an improvement context, the aspect most discussed is motivation 
and willingness to adapt to change; e.g., some critical issues for increasing people's engagement are through emotional and cultural challenges (Bate et al., 2008). If a change easily fits into existing values, then it will also be easier to incorporate it in daily work. Knowledge about people's different responses to change are important and are sometimes based on behavioral psychology (Rogers, 2003).

Deming emphasized leadership and stated that transformation requires capable leaders. In their total quality management (TQM) article, Hackman and Wageman (1995) highlight leadership and management, stating that service quality depends on the system that managers create. Successful and sustainable QI work must contain management commitment and support. In their framework for improvement, Batalden and Stoltz (1993) mention QI leadership policy, including engaged and supportive leaders who understand profound knowledge domains. In QI, leaders at meso- and macro-levels need to understand their role as support and create prerequisites for micro systems to interact and improve (Nelson et al., 2007). The manager's role is to facilitate change without pointing out specific solutions, but instead letting staff initiate change initiatives (Beer et al., 1990).

Even though the human aspect is highlighted, it is not the primary focus and there is little improvement leadership research (Battilana et al., 2010; Eisenbach et al., 1999; Waldman et al., 1998; Øvretveit, 2009). Most organizational change literature is built upon the assumption that leaders possess competences and skills, and leadership literature does not account for the complexity in organizational change activities (Battilana et al., 2010). A literature review found few empirical studies on managing improvement and there are few studies that address what leadership actions promote successful change (Øvretveit, 2009).

When introducing change, some reaction is expected, and the way to handle that in the QI area is to communicate early and explain change process 'why' and 'how' while engaging and encouraging people to take part in the change process, and be committed. Another approach to reduce resistance is to use QI methods, especially the PDSA wheel, where change can be tried out in small steps, raising awareness and involvement in the process along the way, not letting the change 'drop down' on them from above, as something that (top) managers have decided (Beer and Nohria, 2000). Involvement helps to understand change, which motivates adopting new working methods. It will also facilitate the change if it is integrated in the organization's values and beliefs, so that health and welfare staff can more easily identify the benefits and see how the change can contribute to the work, becoming an improvement (Batalden and Stoltz, 1993), which can be compared to the Rogers resistant model (2003), who identified different stages of how people react to change. He also identified crucial factors for change to be sustainable, in alignment with organizational values and beliefs, which in many ways are the same as those highlighted by Batalden and Stoltz (1993) in their QI framework.

\section{Measurements and variation}

Another way to motivate people to improve is measuring. Knowing how you are doing and what needs to be done better also encourages and motivates people to improve, since (almost) everyone wants to do a good job and deliver high quality patient care (Nelson et al., 2007). In QI, feedback is an important part in measurement (variation). To improve services, we need to know how we are doing today and to know that change is an improvement, and we also need data to compare. In contrast to research, QI uses measurements (data) to follow the change at a local level, and therefore it is not sufficient to measure only before and after, which is the usual method in (natural) sciences. This systematically repeated measurement works as feedback for the system if the improvement worked as planned or if further changes needed and tested (cf. PDSA wheel). 
Feedback can also be seen from the human perspective, used to encourage and motivate participation in improvement efforts (Langley et al., 2009).

\section{Adult development}

Adult development is a subfield within developmental psychology, which traces development beyond adolescence. It provides research on systematic and qualitative changes following interaction with internal and external environments (Hoare, 2011). Adult development comprises several personality development theories and in recent decades, much empirical evidence has been assembled to support these theories (Kjellström and Stålne, 2017). Development in this field refers to sequential growth in consciousness complexity. Empirically based theories depict a transformational process in the organizing making meaning structures. This process involves qualitatively different changes in the way that a person organizes his/her own meaning-making. Various concepts are used to describe various stages and ways to interpret the world: meaningmaking systems, action logics and leadership agility. We use action logics as a primary framework, following Torbert's (2004) work but using the labels from Joiner and Josephs (2006). A person's action logic influences his/her awareness and what that person can describe, influence and change. Personality development occurs along pre-conventional stages, to conventional and possibly to post-conventional stages (Kohlberg, 1971; 1981). Development has strong predictive validity in relation to wide ranging working life issues; e.g., competence and leadership agility (Joiner and Josephs, 2006; Rooke and Torbert, 2005; Realms 2017), views and attitudes; e.g., care, responsibility, tolerance and discrimination (Juujärvi et al., 2012; Kjellström and Ross, 2011; Sjölander et al., 2014).

\section{Adult development and change for improvement}

Leading change has been identified as a main area within constructive development leadership research (McCauley et al., 2006). Key researchers, like William Torbert, became interested in QI in the early 1980s (Dunbar et al., 1982), later adding adult development (Fisher and Torbert, 1995). The interest in leading change issues is illustrated in titles like Personal and Organizational Transformations: The True Challenge of Generating Continual Quality Improvement (Fisher and Torbert, 1995), Change Leadership: A Practical Guide to Transforming Our Schools (Wagner et al., 2005) and Leadership Agility: Five Levels of Mastery for Anticipating and Initiating Change (Joiner and Josephs, 2006). The emphasis is on work life improvements, but there is also some research on social change agents (Jordan, 2011). We distinguish three ways in which improvement and change work have been addressed within adult development. First, people with different action logics have qualitatively different understanding and approaches to change work. Second, more complex action logics seem to be needed to create transformational changes and learning. Third, system knowledge is a developmental capacity. Additionally, care's developmental nature is essential to quality health care.

People with different action logics think, talk and act differently in change work

Adult development's core is that people make meaning in different ways, which affects the way they perceive their work and professional roles, which means that people at different life stages are motivated by different values, goals and have different action logics. The most relevant action logics used by adults in work life are: ‘experts', 'achievers', 'catalysts' and 'co-creators' (Joseph and Joiner, 2006). The main capacities regarding each action logics and the possibilities they bring to improvement efforts is described below. But people are dynamic, interdependent and reactive, which means that people do not always have the competence to use these capacities and that each 
action logics has it pros and cons (Herdman-Barker and Erfan, 2015; Herdman-Barker and Wallis, 2016). 'Experts' are interested in efficiency; e.g., doing things optimally like trying to make something faster or less expensive. There is a focus on tactics and solving problems within one's own unit, but little interest in stakeholder views. 'Experts' thrive when they are in environments where success can be achieved by making incremental improvements to existing strategies (Joiner and Josephs, 2006). 'Achievers' expand their time awareness and focus on organization effectiveness. A main question in focus is: Are workers achieving their goals and doing the right tasks? 'Achievers' optimize results in the current system, which can be either local or global (McEwen and Schmidt, 2007). Initiatives include analysing one's industry, which includes strategies to buy-in stakeholders. Continuous improvements are created based upon self-chosen values. They can achieve more strategic thinking and can lead in environments where the organizational strategies need to shift (Joiner and Josephs, 2006). 'Achievers' can sustain and intently direct single-loop learning effectively (McGuire et al., 2007).

The first two action logics belong to what is described as 'heroic' levels; i.e., the leader has all the answers. In post-heroic levels, the leader invites others to co-create answers (Joiner and Josephs, 2006). This post-heroic level is also described as the move from a conventional phase, where societal norms are taken for granted, to a post-conventional phase, where fundamental assumptions are being questioned. When changing, people with a post-conventional framework can create transformational change in their organizations (Rooke and Torbert, 2005), represented by about $15 \%$ of all leaders. 'Catalysts' have a willingness to question underlying business assumptions, which enables them to lead change in highly complex and dynamic environments. Leaders try to create a culture that promotes teamwork, participation and empowerment (Joiner and Josephs, 2006). Catalysts have a genuine interest and appreciate the unique perspectives that each stakeholder brings to an issue. 'Co-creators' develop abilities to lead transformative change, which involves whole system improvement and change in culture and practice (Torbert, 2004; Torbert and Rooke, 1998; Rooke and Torbert 2005). Co-creators have the meaning-making capacities required to rethink assumptions and goals, and weave together short-term and long-term processes, which also includes the capability to link overarching principles with strategies and system interactions, where everyone works towards common goals, is essential. Stakeholders are not only appreciated but actively used as a tool for improving decision-making. Initiating work on corporate responsibility and sustainability within units or whole organizations is predominant (Joiner and Josephs, 2006), and they can create a culture with focus on teamwork, participation and empowerment. With this framework, a person has the capacity to initiate and sustain doubleloop learning, which is shown to be a prerequisite for creating environments for personal and organizational transformation (Bushe and Gibbs, 1990; McCauley et al., 2006; McGuire et al., 2007; Torbert and Rooke, 1998; 2005). Further development beyond co-creator is possible but rare and involves an even deeper and more intuitive working with colleagues and stakeholders, and facilitates triple-loop learning.

\section{More complex frames facilitate transformative change}

A central proposition is that leaders at later development stages are more effective at leading transformative change. The argument is that it is only when they reach post-heroic levels, can they become co-creator action logics and are interested in and able to rethink assumptions (e.g., engage in double-loop learning) (McCauley et al., 2006 and Baron and Cayer, 2011). Managers and consultants at later stages focus on cultural change as the leader's task (Weathersby, 1993), manage to create transformative changes (Torbert and Rooke, 1998) and were regarded as more competent in leading organizational change initiatives (Bushe and Gibbs, 1990). Similar patterns have been 
identified in sustainability projects, where those most interested in performing transformational changes are those with later action logics, who also have the capacities to see all systems (environment, social and economic) that need to be integrated (Baron and Cayer, 2011; Boiral et al., 2014; Boiral et al., 2009; Brown, 2011; 2012; Inglis, 2008; McEwen and Schmidt, 2007). There is mixed support for the proposition that later action logics creates leadership effectiveness (McCauley et al., 2006), which could be explained by complex human beings and all persons having strengths and weaknesses in unique combinations (Herdman-Barker, 2016).

\section{System knowledge development}

The theory that clearly and comprehensively focuses on system knowledge is the hierarchical Complexity Model (Commons and Ross, 2008a), which is applicable in all cases where information is organized, and how complex information is managed and coordinated. Improvement work builds upon system knowledge, but only 20\% of the population can use systematic thinking usupported (Commons and Ross, 2008b). Systematic reasoning is required to provide insight into how multiple input is put together to create a coherent system, unlike the formal level where there is only one variable as input. Forming systems from several interacting formal relations becomes possible, such as a micro, economic or eco systems. Systematic reasoning also brings contextual awareness; i.e., insight that various factors may have different relevance in different contexts, which means that we can put the events and ideas in a larger context and consider relationships in different contexts. With systems thinking, one can identify and discuss processes; e.g., virtuous (vicious) circles, feedback loops and distinguish between correlation and causality. Meta-systematic reasoning integrates multiple systems or perspectives and creates the ability to relate to and observe different systems, which forms the foundation for discussing system characteristics as consistent or comparable. At this level, one can reflect on and set properties on the system or assumptions on which that system is based. People who use this thinking level can compare different systems and perspectives systematically in many different areas. It is possible to compare, construct, transform and/or synthesize different systems by ensuring the system's properties, or individuals within the systems. It is estimated that $1-2 \%$ of the population consistently uses meta-systematic thinking (Commons and Ross, 2008b).

\section{Providing good quality care - mental demands}

There are many important service quality factors provided through the health and welfare systems; e.g., economic conditions, housing facilities, access to technical aids, ambitions in guidelines and legislation, improvement work performed, and education level/quality. One factor is interpersonal cognitive complexity; i.e., ability to perceive others in complex and personalized ways, be more empathetic and improved capacity to understand other perspectives and to relate to a caretaker in a more person-centered way (Grosch et al., 2011; Juujärvi et al., 2012; Medvene, et al., 2006). One study examined nursing assistants' views of good care. Compared to socio-demographic and occupational factors, the value systems (a way to measure adult development) had stronger predictive impact on staff views on care ethics and on participation and autonomy among the elderly (Kjellström and Sjölander, 2013). The views among staff with early conventional value system (equivalent to an action logic preceding the 'expert') were to a large extent related to strict rules, routines, their own working conditions and how they would like to be cared for when old, while the views among those with middle value system ('expert' action logic), in particular, late conventional value systems ('achiever' action logic) were based on collaboration between the older person and staff, on individualization and elderly needs and preferences. We conclude that staff at late conventional development stages show value priorities that are most in accordance 
optimizing the older person's autonomy while minimizing paternalism, which is required for professionalism. Genuinely appreciating inter-professional team perspectives is a later stage attribute (Juujärvi et al., 2010).

\section{Discussion}

The simplest answer to why understanding personal development theory is important for facilitating organizational development and change, is that it provides fundamental insights into how differently people make meaning of change work. More fundamentally, there seems to be poor awareness of the mental demands and need for capabilities that care and improvement work put on people, which is a prominent theme in adult development research (Kjellström and Stålne, 2017).

\section{QI mental demands}

The mental demands of several QI practices are both high and neglected within QI and IS. Competences that are taken for granted in QI, which according to adult development require rather high complexity in meaning-making, are system knowledge and being able to work in interprofessional teams and truly appreciate other perspectives. Feedback and resistance to change is another example. Research shows that different action logics make people more or less positive to feedback, which is essential in change work. The general trend is that people are negative to feedback at early action logics and through development they become increasingly interested and positive about feedback (Cook-Greuter, 2005; Torbert, 2004). McGuire et al., (2007) claim that all stages up to diplomat have an orientation that resists change. 'Expert' and 'achiever' action logics are positive to incremental and single-loop change. More complex action logics such as 'cocreators' allow double-loop and even triple-loop change that varies with the situation (Torbert, 2004), which shows that adult development theories can provide useful knowledge that acknowledges and respects individual differences.

Many improvement ideas and practices seem to require a post-conventional framework to be fully possessed, which means that structures and environments need to be created to support people involved in improvement practice. This should not be interpreted as if everybody needs to have a 'co-creator' action logic, but at least one and preferably a few leaders need to have this capability to create the processes and structures supporting workplace improvements (Leitch et al., 2015). Most authors discuss different ways of handling change, but McEwen and Schmitd (2007) take this a step further and propose that persons with different action logics prefer and can use different improvement models. A good model for 'experts' and 'achievers' is Kotter's eightstep change model. 'Achievers' and 'catalysts' can use Kurt Lewin's three-step model as a translational approach; transformational models for them are: Dee Hock's Charordic approach, Clare Graves' Change States and Ron Heifetz's Adaptive Change Strategies (McEwen and Schmidt, 2007). These connections to different actions logics and preferred change models have not been empirically tested and need to be explored. Adult development (AD) theory can help to break down the four QI domains (profound knowledge) into parts at different development levels, so that the demands on people are not that complex in AD terms, and could therefore be a good way to start improvement development. In contrast, just focusing on high-level visions or goals could be overwhelming for some and, therefore, demotivating rather than encouraging.

\section{Leadership for change}

Leadership is acknowledged within QI and IS as change's human side, but given adult development research on leadership importance and that several leaders have the required action 
logics, leadership is given less attention than it deserves and requires. Adult development claims that change leaders must look outward to facilitate change in the organization and inward to understand why it is difficult for individuals to change (Helsing et al., 2008). Quality improvement could benefit if change difficulties were highlighted more. Claiming that everyone has two jobs, doing it and making it better (Batalden and Davidoff, 2007) should also involve ways to accomplish both professional tasks and improvement work. Therefore, AD can add valuable insights, not least to leaders, on what demands they put on staff and what support is needed. Developmentally aware leadership means that leaders need to be more patient and understand that change takes time (Kegan and Lahey, 2009; Kjellström, 2009, 2010). Leaders need to understand what they need to do to facilitate improvement, so that everyone can contribute, based on their capacity. Improvement science is a multidisciplinary framework, which requires acknowledging different disciplines that places mental demand on researchers. Adult development seems to be a promising field to add to the IS palette.

\section{References}

Argyris, C. (1999), On organizational learning, Blackwell, Oxford.

Baron, C. and Cayer, M. (2011), 'Fostering post-conventional consciousness in leaders: why and how?', Journal of Management Development, Vol. 30 No. 4, pp. 344-365.

Batalden, P.B. and Davidoff, F. (2007), 'What is "quality improvement" and how can it transform healthcare?', Quality and Safety in Health Care, Vol. 16, pp. 2-3.

Batalden, P.B. and Stoltz, P.K. (1993), 'A framework for the Continual Improvement of Health Care: Building and Applying Professional and Improvement Knowledge to Test Changes in Daily Work', Journal on Quality Improvement, Vol. 19 No. 10, pp. 424-447.

Battilana, J., Gilmartin, M., Sengul, M., Pache, A.C. and Alexander, J.A. (2010), 'Leadership competencies for implementing planned organizational change’, The Leadership Quarterly, Vol. 21 No. 3, pp. 422-438.

Bate, P., Mendel, P. and Robert, G. (2008), Organizing for Quality, Radcliff Publishing, Oxford.

Bergman, B., Hellström, A., Lifvergren, S. and Gistavsson, S.M. (2015), 'An Emerging Science of Improvement in Health Care’, Quality Engineering, Vol. 27, pp. 17-34.

Beer, M. and Nohria, N. (2000, Eds.), Breaking the Code of Change, Harvard Business School Press, Cambridge, MA.

Beer, M., Eisenstat, R.A. and Spector, B. (1990), 'Why Change Programs Don't Produce Change, Harvard Business Review, November-December, pp. 158-166.

Boiral. O., Baron, C. and Gunnlaugson, O. (2014), 'Environmental leadership and consciousness development: A case study among Canadian SMEs', Journal of Business Ethics, Vol. 123 No. 3, pp. 363-383.

Borial, O., Cayer, M. and Baron, C.M. (2009), 'The action logics of environmental leadership: A developmental perspective’, Journal of Business Ethics, Vol. 85 No. 4, pp. 479-499.

Brown, B.C. (2011), Conscious Leadership for Sustainability: How leaders with a late-stage action logics design and engage in sustainability initiatives, unpublished $\mathrm{PhD}$ thesis, Fielding Graduate University.

Brown, B.C. (2012), 'Leading complex change with post-conventional consciousness', Journal of Organizational Change Management, Vol. 25 No. 4, pp. 560-575.

Bushe, G.R. and Gibbs, B.W. (1990), 'Predicting organization development consulting competence from the Myers-Briggs Type Indicator and stage of ego development', The Journal of Applied Behavioral Science, Vol. 26 No.3, pp. 337-357. 
Commons, M.L. and Ross, S.N. (2008a), Special Issue: Postformal Thought and Hierarchial complexity, World Future: Journal of General Evolution, Vol. 64 No. 5-7, pp. 297-562.

Commons, M.L. and Ross, S.N. (2008b), 'What postformal thoughts is, and why it matters', World Future: Journal of General Evolution, Vol. 64 No. 5-7, pp. 321-329.

Cook-Greuter, S.R. (2005), 'Making the case for developmental perspective', Industrial and Comercial Training, Vol. 36 No. 7, pp. 275-281.

Deming, W.E. (2000), Out of the Crisis, MIT Press, Cambridge, MA.

Donabedian, A. (2003), An Introduction to Quality Assurance in Health Care, Oxford University Press, Oxford.

Dunbar, R.L., Dutton, J.M. and Torbert, W.R. (1982), 'Crossing mother: Ideological constraints on organizational improvement’, Journal of Management Studies, Vol. 19 No. 1, pp. 91108.

Eisenbach, R., Watson, K. and Pillai, R. (1999), 'Transformational leadership in the context of organizational change', Journal of Organizational Change Management, Vol. 12 No. 2, pp. 80-98.

Fisher, D. and Torbert, W.R. (1995), Personal and organizationel transformations: The true challenge of continual quality improvement, McGraw-Hill, Ohio.

Glouberman, S. and Zimmerman, B. (2002), 'Complicated and Complex systems: What Would Successful Reform of Medicare Look Like', Commission on the Future of Health Care in Canada, Discussion paper, No. 8.

Grosch, K., Medvene, L. and Walker, D. (2011), 'Using a measure of person-perception skills to identify outstanding home care workers', Home Health Care Services Quaterly, Vol. 30 No. 1, pp. 24-41.

Hackman, J.R. and Wageman, R. (1995), 'Total Quality Management: Empirical, Conceptual, and Practical Issues’, Administrative Science Quarterly, Vol. 40, pp. 309-342.

Helsing, D., Howell, A., Kegan, R. and Lahey, L. (2008), 'Putting the "development” in professional development: Understanding and overturning educational leaders' immunities to change', Harvard Educational Review, Vol. 78 No. 3, pp. 437-465.

Herdman-Barker, E. and Erfan, A. (2015), Clearing Obstacles in Action Inquiry: An Exercise to Expand a Person's Repertoire of Action, in: Bradbury, H. (Ed.), The SAGE handbook of action research, $3^{\text {rd }}$ ed., Sage, London, pp. 626-635.

Herdman-Barker, E. and Wallis, N.C. (2016), 'Imperfect Beauty: Hierarchy and Fluidy in Leadership Development', Challenging Organisations and Society, Vol. 5 No. 1, pp. 117.

Hoare, C. (2011, Ed.), The oxford Handbook of Reciprocal Adult Development and Learning, Oxford University Press, Oxford.

Hovlid, E., Bukve, O., Haug, K., Aslaksen, A.B. and von Plessen, C. (2012), 'Sustainability of healthcare improvement: what can we learn from learning theory?', BMC Health Service Research, $\quad$ Vol. 12 No. 235, avaliable at: http://bmchealthservres.biomedcentral.com/articles/10.1186/1472-6963-12-235, (accessed 15 March 2017).

Inglis, J. (2008), 'Evolving to address global climate change and the scale of public interactions', World Futures: The Journal of General Evolution, Vol. 64 No. 5, pp. 503-512.

IoM (Institute of Medicine) (2001), Crossing the Quality Chasm: A New Health System for the $21^{\text {st }}$ Century, National Academy Press, Washington, DC. 
Joiner, W.B. and Josephs, S.A. (2006), Leadership Agility: Five Levels of Mastery for Anticipating and Initiating Change, Jossey-Bass, San Francisco, CA.

Jordan, T. (2011), 'Skillful engagement with wicked Issues: a framework for analyzing the meaning-making structures of social change agents', Integral Review, Vol. 7, pp. 47-91.

Juujärvi, S., Myyry, L. and Pesso, K. (2010), 'Does care reasoning make a difference? Relations between care, justice and dispositional empathy’, Journal of Moral Education, Vol. 39 No. 4, pp. 469-489.

Juujärvi, S., Myyry, L. and Pesso, K. (2012), 'Empathy and values as predictors of care development', Scandinavian Journal of Psychology, Vol. 53 No. 5, pp. 413-420.

Kegan, R. (1994), In Over Our Heads: The Mental Demands of Modern Life, Harvard University Press, Cambridge, Mass.

Kegan, R and L.L. Lahey (2009) Immunity to change: How to overcome it and unlock potential in yourself and your organization. Harvard Business Press.Cambridge, Mass.

Kjellström, S. (2009), 'The Ethics of Promoting and Assigning Adult Developmental Exercises: A Critical Analysis of the Immunity to Change Process', Integral Review, Vol. 5 No. 2, pp. 116-132.

Kjellström, S. (2010), 'Responsibility and Ethica in the Use and Advocacy of Developmental Exercises: Response to Zeitler and Reams’, Integral Review, Vol. 6 No. 2, pp. 19-28.

Kjellström, S. and Ross, S.N. (2011), 'Older persons reasoning about responsibility for health: variations and predictions’, International Journal of Aging and Human Development, Vol. 73 No. 2, pp. 99-124.

Kjellström, S. and Sjölander, P. (2013), 'The level of development of nursing staff's value system predicts their views on paternalistic care and personal autonomy', International Journal of Aging and Later Life, Vol. 9 No. 1, pp. 35-68.

Kjellström, S. and Stålne, K. (2017), 'Adult development as a lens: Applications of adult development theories in research', Behavioral Development Bulletin, avaliable at: http://dx.doi.org/10.1037/bdb0000053, accessed 15 March 2017.

Kohlberg, L. (1971), 'Stages of moral development', in Beck, C.M., Crittenden, B.S. and Sulivan, E.V. (Eds.), Moral Education, University of Toronta Press, Toronto, pp. 23-92.

Kohlberg, L. (1981), Essays on Moral Development, Harper and Row, San Fransisco.

Langley, G.J., Moen, R.D., Nolan, K.M., Nolan, T.W., Norman, C.L. and Provost, P.L. (2009), The Improvement Guide: A practical approach to enhancing organizational performance, $2^{\text {nd }}$ ed., Jossey-Bass, San Fransisco.

Leitch, D., Rooke, L. and Wilson, R. (2015), 'The Hidden Talent: Ten ways to identify and retain transformational leaders', <http://harthill.co.uk/harthill-recources/articles-and-papers/>, accessed March 2017.

Marshall, M., Pronovost, P. and Dixon-Woods, M. (2013), 'Promotion if improvement as a science', The Lancet, Vol. 381 No. 9864, pp. 419-421.

McCauley, C.D., Drath, W.H., Palus, C.J., O’Connor, P.M.G. and Baker, B.A. (2006), 'The use of constructive-developmental theory to advance the understanding of leadership', The Leadership Quarterly, Vol. 17, pp. 634-653.

McEwen, C.A. and Schmidt, J.D. (2007), 'Leadership and the corporate sustainability challenge: Mindset in action', <SSRN 1118071>, accessed March 2017.

McGuire, J., Palus, C.J. and Torbert, W. (2007), Toward interdependent organizing and researching, in Shani, A.B., Albers Mohrman, S., Pasmore, A., Stymne, B. and Adler, N. 
(Eds.), Handbook of Collaborative Management Research, Sage Publications, London, pp. 123-142.

Mezirow, J. (1991), Transformative Dimensions of Audult Learning, Jossey-Bass, San Fransisco. Medvene, L., Grosch, K. and Swink, N. (2006), 'Interpersonal complexity: A cognitive component of person-centered care’, The Gerontologist, Vol 46 No 2, pp. 220-226.

Mohr, J.J. and Batalden, P.B. (2002), 'Improving safety on the ront lines: the role of clinical microsystems', Quality and Safety in Health Care, Vol. 11, pp. 45-50.

Nelson, E.C., Batalden, P.B. and Godfrey, M.M. (2007, Eds.), Quality by Design: A Clinical Microsystems Approach, Jossey-Bass, San Fransisco.

Øvretveit, J. (2009), Leading improvement effectively. Review of Reseach, The Health Foundation, London.

Palmberg, P. (2009), Complex adaptive systems. Properties and approaches, Research Report Luleå University of Technology, Luleå, Sweden.

Reams, J. (2016), An Overview of Adult Cognitive Development Research and Its Application in the Field of Leadership Studies, Behavioral Development Bulletin, December, avaliable at: http://dx.doi.org/10.1037/bdb0000032, accessed 15 March 2017.

Riley, W.J., Moran, J.W., Corso, L.C., Beitsch, L.M., Bialek, R. and Cofsky, A. (2010), 'Defining Quality Improvement in Public Health', Journal of Public Health Management and Practice, Vol. 16 No. 1, pp. 5-7.

Rogers, E.M. (2003), Diffusion of Innovations, $5^{\text {th }}$ ed., Simon and Schuster International.

Rooke, D. and Torbert, W.R. (2005), 'Seven Transformations of Leadership', Harvard Business Review, April, pp. 1-11.

Senge, P.M. (2000), The Puzzles and Paradoxes of How Living Companies Create Wealth: Why Singled-Valued Objective Functions Are Not Quite Enough, in Beer, M. and Nohria, N. (Eds.), Breaking the Code of Change, Harvard Business School Press, Cambridge, MA, pp. 59-81.

Sjölander, P., Lindström, N., Ericsson, A. and Kjellström, S. (2014), 'A pattern recognition methodfor disclosing different levels of value system from questionnaire data', Behavioral Development Bulletin, Vol. 19 No. 3, pp. 114-127.

Ting, H.H., Shojania, K.G., Montori, V.M. and Bradley, E.H. (2009), 'Quality Improvement: Science and Action', Circulation, Vol. 119, pp. 1962-1974.

Torbert, W.R. (2004), Action Inquiry: The Secret of Timely and Transforming Leadership, BerrettKoehler, San Fransisco, CA.

Torbert, W.R. and Rooke, D. (1998), 'Organizational Transformation as a function of CEOs'developmental Stage', Organization Development Journal, Vol. 16 No. 1, pp. 1128.

Wagner, T., Kegan, R., Lahey, L.L., Lemons, R.W., Garnier, J., Helsing, D., Howell, A., Thurber Rasmussen, H. and Vander Ark, T. (2005), Change Leadership: A Practical Guide to Transforming Our Schools, Wiley and Sons, New York.

Waldman, D.A., Lituchy, T., Gopalakrishnan, M., Laframboise, K., Galperin, B. and Kaltsounakis, Z. (1998), 'A qualitative analysis of leadership and quality improvement', The Leadership Quaterly, Vol. 9 No. 2, pp. 177-201.

Weathersby, R. (1993), Sri Lankan managers' leadership conceptualizations as a funtion of ego development, in, Demick, J. and Miller, P.M. (Eds.), Development in the Workplace, Lawrence Erlbaum Associates, Hillsdale, pp. 67-89. 